tend to write at any length. Dr. Dick has been pleased to say that I take virtually the same view of the question as he does himself; there is, however, this palpable difference between us-he denies the truth of phrenology, and I do not. I only quarrel with the application which some phrenologists would make of it.

On a subject like phrenology, there must be much variety of opinion amongst phrenologists themselves; and I think, though perhaps erroneously, that a few of them are becoming very hobby-horsical. With regard to the difference between physical and mental actions, and the consequent irresponsilility of the former and the responsibility of the latter, I must beg leave to draw your attention to the forcibly-expressed opinions of Hazlitt, who thus states the matter very clearly:-

"The sword and the assassin would be equally moral and accountable agents, if they were both equally accessible to moral motives, that is, to reward and punishment, praise and blame, \&c.; but they are not. This seems to be a distinction of great pith and moment. * * * It is objected, indeed, that still both are equally necessary agents; but this appears to me to be a confusion of words. It is in vain to exhort flame not to burn, or to be angry with poison for working; and it would be equally rain to exhort men to certain actions and to resent others, if exhortation and resentment had no more effect upon them, that is, if they were really governed by the same sort of blind, physical, unreasoning, unresisting necessity."

The proper province of phrenology is to show the ingredients which form our character, and their relative proportions; but what is their jntensity, how they influence each other, and what circumstances have excited and will excite them into action, it can by no means precisely determine. Did I not believe that man can err wilfully, with a clear view of right and wrong before $h \mathrm{im}$, and the power of choosing between the two, I should deem the punishments of our courts of justice the unnecessary tortures of the helpless victims of mal-organised brains. I am, \&c.

Spectator.

\section{DOCTRINES OF SPURZHEIM.}

\section{To the Editor of The LA NCET.}

Sir,-It has struck me that much of the discussion on "criminal legislation" would have been prevented, if the advocates of phrenology had stated what Dr. Spurzheim taught, that from the development of a man no positive conclusion can be derived as to the actions he will perform. Hence reflecting phrenologisis never predicate actions but merely tendencies. To support the contrary doctrine, is to advance the untenable posi- tions of fatalism; a doctrine which Spurzheim would as much thought of sanctioning as of adrocating the creed of Mahomet. Phrenologists should therefore be cautious how they lead their opponents astray as regards their opinions.

Dr. Dick has, however, fallen into a striking error; for he supposes that phrenologists are as one respecting the principles of criminal legislation. Now this notion is incorrect. When, for instance, Mr. Sampson advances his opinions, he merely advances the opinion of an individual phrenologist, and not necessarily the doctrines of the school; and thus in advocating his opinions, he nay support positions with which other phrenologists may disagree. Never, therefore, let $\mathbf{D r}$. Dick conclude that because one phrenologist writes so and so, all phrenologists necessarily think the same. Each phrenologist, like the advocates of other sciences, must be judged by his own merits. I am, Sir, yours respectfully,

May 21, 1812 .

H. B. Brooks.

\section{MEMORIAL}

To

\section{THE SENATE OF THE UNIVERSITY OF LONDON.}

\section{To the Editor of The LANCET.}

Sir,--Knowing that you have continually exerted yourself in the examination and exposure of corporate misdeeds, I have forwarded to you the inclosed memorial to the senate of the University of London, together with the correspondence between the registrar, examiners, and myself. We might have expected better things from a new institution, anxious, as it ought to be, to obtain an honourable position among the universities of Great Britain. The "regulations" state that at the examination for the M.D. degree, " any candidate may present a thesis on a subject of his own choice. If in the opinion of the examiners sufficient merit be evinced, a gold medal of the value of $10 l$. shall be given to the author of the best thesis. The examiners shall not be precluded from examining the author on the subject of his thesis." Such is the notice of the thesis in the regulations. It leaves to the candidate the choice of his subject among any of the medical sciences. I availed myself of the latitude of the "regulations," and wrote one on the generation of organised beings. This thesis was not even seen by the examiners in botany and physiology, within whose province it came, but, as I believe, by the examiners in medicine-pretty judges, forsooth, on such a subject! To have complained that injustice was done me, had the examiners in animal and vegetable physiology perused my thesis, would have been the height of folly 
and absurdity; but to complain, as $I$ do, that these examiners did not even see the thesis, is in no degree improper, the examiners in medicine not being officially (if competent as scientific men) proper judges on such a subject. But to crown all, the senate takes the examiners by the hand and says, that they have acted justly and properly in ascertaining the merits of a work on a subject with which they were officially unacquainted. The virtual assertion by the senate, that any one or two of the examiners are capable of examining on any or all subjects would, if fully acted on, create a pretty confusion in the affairs of the university. We shall next have the examiner in Latin or Greek settling medical and physiological questions; and he might do so with fully as great propriety as the examiners in medicine have done in my case. The senate have, in justifying the examiners, done much the same thing as a private person would do if he repeatedly went to his tailor for a joint of meat, or vice versa; he would be transferred to a very proper place for him-a lunatic asylum. I need not further enlarge on the folly of the principle, that the senate of the University of London have enunciated; it is sufticiently glaring, and speaks for itself. I am, Sir, your obedient servant,

Philip B. Ayres.

"My Lords and Gentlemen,-The examiners of the London University having awarded no prize for the theses sent in by the candidates for the degree of doctor of medicine at the last examination, although either three or five were presented; and there having been, from what I can learn, some irregularity in their proceedings, I am tempted to memorialise you on the subject, not so much for myself, for I have had sufficient experience to be aware that the acts of public bodies are for the most part irrevocable, as for the information and benefit of future candidates who may, like myself, waste their time and energies in a hopeless scheme.

"For this reason, simply, I now make application to you to investigate the circumstances under which the above theses were examined, and their merits, or rather their want of all merit, determined.

"For my own part, and as far as my thesis is concerned, I may say that although it contained no original research, yet I flattered myself that both its plan, and some of the ideas and reasonings it contained, were original, and sufficiently proved by the facts collected from the best writers at my command. As I had not the advantages of a large library at hand, it could not contain mauy facts that $I$ would otherwise have gladly introduced, and some of the statements may have been disproved by subsequent investigators. The subject was one of the most obscure functions of organised beings-their reproduction. The leading idea of the thesis arose from the great division of labour which has taken place, not only in manufactures but also in scientific subjects, causing men to follow particular branches of science, to the neglect of the remainder, and thereby rendering them unfit for the general comparison of the whole series of organised beings.

"It also occurred to me that the process of reproduction in the two great divisions of organised beings presented striking simila. rities, and that a careful examination of the function in the two classes would enable ne to bring the whole under certain general laws equally applicable to animals and plants, This, I fondly conceived, I had done in my thesis, which took up the whole of the little leisure afforded by my practice during seve. ral months. Having consumed so much time and mental energy on its production (which was doubtless the case with the other candi. dates who presented theses), I certainly did not anticipate for it the treatment it has received at the hands of your examiners. Had any one of the theses received the prize, or even honorary mention, I should have bowed with submission to the decision of the exa. miners ; but as all were among the 'rejected addresses,' I could not but imagine that they had not received a careful perusal. I am aware of the fondness of authors for their writings, but I would not be so rain as to think that mine was the most meritorious.

"Some private information, which I need not now mention, first led me to suspect that the examination of my thesis was not faily conducted; and $I$ now possess sufficient and authentic information to warrant me in affirming that this was the case. I therefore feallessly assert, that the conduct of certain of the examiners and officers has been most disgraceful to the university, and that such conduct (if continued) will greatly injure it in the estimation of the public. ... It is therefore the duty of the senate to make in. quiries on the subject, and remove those ofticers who have acted in this unfair and disgraceful manner.

"I now proceed to the evidence on which my assertions are grounded, which will, I doubt not, be found strong and conclusire. The subject of my thesis being physiological, and including the two branches of animal and vegetable physiology, I, of course, ex. pected that it would have been submitted to Professor Henslow and Dr. Roget, the two examiners on those subjects, who were undoubtedly the proper judges of its merits or demerits. No announcement having been made of the result of the theses by the 16th of December (more than a month after the examination), I wrote to the registrar the note marked No. 1, inquiring whether ans adjudication had taken place, and to which of the examiners my thesis had been subjected for decision; at the same time I requested 
the return of the copy of my thesis sent in at the examination. I received an answer from him (No.2), dated Dec. 20, stating that the examiners had made no report on the subject, and that he regretted that he could not return the copy of the thesis. I again wrote to him on the 22nd (No. 3), requesting a more explicit reply with respect to the adjudication, and as to which of the examiner's had inspected my thesis.

"I received a reply (No. 4), bearing date Dec. 23rd, stating that no prize was adjudicated; that he did not know which of the examiners had examined the thesis; and even if he did know, he should not feel himself at liberty to inform me, as it would sanction what he considered irregular proceedings, namely, private communications between the candidates and examiners. This reply convinced me that it was useless to expect further information from the registrar, and $I$ therefore addressed myself to those examiners who, in my opinion, should have read my thesis, namely, Professor Henslow and Dr. Roget. I accordingly wrote to each of them, simply inquiring whether they had seen the thesis. Professor Henslow immediately replied, that no such thesis had been submitted to him (No.6). As Dr. Roget did not reply to my note for nearly three weeks, I took the liberty of again ad.. dressing $\operatorname{him}\left(\mathrm{No}_{0} 10\right)$, fearing that he had not receired my previous letter, to which $I$ received a rather uncourteous reply (No. 11), stating that he was not an examiner for the degree of doctor of medicine, leaving me to infer that he had not seen my thesis; an inference that I believe to be correct.

"Here closes the correspondence which forms the evidence on which $I$ found $m y$ charge of unfair conduct on the part of certain officers of the university.

"Dr. Roget, unfortunately for the examiners for the M. D. degree, in avoiding a direct answer to my question implicates them in the transaction. He permits the inference that the examiners for that degree adjudicated the merits of my thesis; but even supposing that Dr. Roget did examine my thesis, still I contend that injustice was done me in not subjecting it to Professor Henslow, the only competent judge of minute botanical details. It is sufficiently evident, howerer, that it was not seen even by $\mathbf{D r}$. Roget.

"The examination and adjudication of $\mathrm{my}$ thesis, therefore, rested with the examiners for the M.D. degree. These are the examiners in logic, moral and intellectual philosophy, medicine, surgery, and midwifery. It is not at all probable that either the examiners in logic, moral and intellectual philosophy, surgery, or midwifery, had anything to do with it; the charge, therefore, rests with the examiners in medicine; highly improper persons to adjadicate on a physiological subject,
"On a review of the evidence $I$ have brought forward $I$ accuse the examiners in medicine, Drs. Billing and Tweedie, with having unwarrantably read and adjudicated on my physiological thesis; and I call upon the senate to examine the charge, and on them to rebut the accusation, if they are able to do so.

"Finally, I petition the senate to allow the corrected copy of my thesis, sent in at the examination, to be returned to me, with a view to its publication, in order that others may judge of its merits or demerits.

66 With the hope that these matters will undergo a strict examination, I subscribe myself, your obedient and humble servant,

"Phildr B. Arres, M.D., Lond.

"6 P.S.-Authentic copies of the correspondence will accompany this memorial."

\section{1.-Dr. Ayres to Mr. Rothman.}

"Sir,-You will oblige me by giving the diplomas I left at the university, together with the diploma of doctor of medicine, to Dr. Mackenzie, who will apply for them in my name. At the same time, I shall esteem it a favour if you will inform me what is the result of the theses sent in by several of the candidates, and among them myself. I have as yet received no official information as to the result, since, at the time Mr. Moore wrote to me, no decision had been arrived at. May I, at the same time, ask, to which of the examiners my thesis (being a physiological one) was subjected, for the decision of its merits or demerits? I am sorry that I was induced by the passage relating to the thesis in the 'regulations' to write one that occupied almost the whole of my leisure time for three or four months, and prevented my devoting that time to metaphysics and medicine; to which I may attribute my want of success at the pass examination. Had the regulations been more explicit, they would have saved me the disgrace of being placed in the second class. I am, Sir, Sc.

"Thame, Dec. 16, 1811 .

$$
\text { "Ph. B. Ayres, M.D. }
$$

"P.S.-I hope you will favour me with an early reply. Perhaps you will also oblige me by returning the copy of the thesis I sent in through Dr. Mackenzie, when he applies for it and the diplomas."

$$
\text { 2.-Mr. Rothman to Dr. Ayres. }
$$

"Sir,-Agreeably to your desire all your diplonuas will be given to Dr. Mackenzie when he calls for them. I have received no report whatever from the examiners regarding the theses, and $I$ conclude from this circumstance that it is not their intention to recommend any of them for the gold medal. I regret that it is not in my power to comply with your request of returning your thesis. In the fir'st place, it is not in my hands, but in those of the examiners; and in the second, 
were it deposited with me, I should not feel justified in parting with it, without a special order of the senate, as such a step would be contrary to the practice always hitherto observed in this university. I am anxious to observe, as you desire an early reply, that your letter, though dated the 16th, did not reach Somerset House till this morning, and bears the London post-mark of to-day. I remain, Sir, \&c.

\section{"R. W. Rothman.}

"University of London, Dec. 20, 1841."

\section{3.-Dr. Ayres to Mr. Rothman.}

" $\mathrm{Sir},-\mathrm{I}$ thank you for your prompt attention to my note. Unavoidable circumstances prevented my posting it until the 18th, consequently you received it on Monday, the 20th. I think that, at least, the examiners should formally announce their determination, since until such announcement be made known to us we remain in uncertainty as to the result, and under such circumstances I do not like to trust to inference.

"I expected to hear that you had not the power to return the copies of the theses. This must remain for the decision of the senate, to whom it is my intention to make application.

"You have omitted to answer the most important question in my note; viz. ' to which of the examiners my thesis (being a physiological one) was subjected for the decision of its merits or demerits!' I therefore repeat the question, in order that I may apply to the examiners themselves on the subject.

" $I$ apprehend that Dr. Roget and Professor Henslow are the examiners on whom the decision of my thesis will fall. I shall feel obliged by your giving me their respective addresses. I am, Sir, \&c.

$$
\text { "Ph. B. Ayres, M.D. }
$$

"Thame, Dec. 22, 1841."

$$
\text { 4.-Mr. Rothman to Dr. Ayres. }
$$

"Sir,-I wish to explain that the examiners have already made their report to the senate relative to the late examination for the degree of M.D. That report does not recommend the award of any medal for a thesis; and, consequently, no such medal will be awarded by the senate on this occasion.

"You must excuse my answering your question, "to which of the examiners your thesis was subjected for decision on its merits.' In the first place, I really am ignorant on this point; but were it otherwise, I do not feel that I should be justified in complying with this request. I must also decline sending you the addresses of Dr. Roget and Professor Henslow, as by so doing I should sanction proceedings which I consider irregular, namely, private communications be- tween the candidates and the examiners. am, Sir, \&c.

"University of London,

“ R. W. Rothman. Dec. 23, 1841."

5.-Dr. Ayres to Dr. Ruget and Professo Henslow, respectively.**

"Sir,-You would confer a great obliga tion on me by informing me whether a thesi: presented at the late M.D. examination in the University of London, entitled 'An $E_{s}$ say on the Generation of Organised Beings, was subjected to your scrutiny. An early reply will oblige your obedient servant,

"Thame, Oxon, Jan. 2, 1842." "Ph. B. Ayres, M.D.

$$
\text { 6.-Prof. Henslow to Dr. Ayres. }
$$

" $\mathrm{Sir},-$ The curator of the Botanic Gar. den, Cambridge, has forwarded to me a letter addressed to him, which he supposed you intended for me. I never had the essay you allude to submitted to me as an examiner of the London University. My department is strictly botanical. Yours faithfully,

"Hitcham, Bildeston, Suffolk, "J. S. HeNsLOW, Jan. 8, 1842."

(This is a mistake; the letter was sent to Professor Henslow, under cover to the curator of the garden, Cambridge.)

$7,8,9$. - In reply to an inquiry dated Jan. 9th, 1842, Mr. Rothman iuformed Dr. Ayres on the 12th that a meeting of the senate of the university was fixed for Wednesday, the 19th January, but as Dr. Ayres had received no answer from Dr. Roget, he did not make use of this information.

$$
\text { 10.-Dr. Ayres to Dr. Roget. }
$$

"Sir,-Supposing that you did not receive a note bearing date January 2nd, 1842, which I directed to you in Bernard-street, I beg to be permitted to repeat the question therein contained, whether a thesis entitled - An Essay on the Generation of Organised Beings' was subjected to your scrutiny? Will you be so kind as to favour me with an answer at your earliest convenience. I am, Sir, \&c.

"Thame, Oxon, Jan. 27, 1842."

$$
\text { " Ph. B. Ayres, M.D. }
$$

$$
\text { 11.-Dr. Roget to Dr. Ayres. }
$$

"Sir,-I did not think it necessary to write an answer to your first letter, becaus? I imagined that, before you could have received that answer, you would have disevered, on referring to the regulations, that I am not appointed an examiner for the degree of doctor in medicine; and also that you would have felt, on reflection, that the pro. per person to whom you ought to apply for

* A copy was sent to each examiner. 
information relative to the examinations is the registrar and not the examiners. Your obedient servant,

"Bernard-street, London, Jan. 28, 1842."

Dr. Ayres was now informed by $\mathrm{Mr}$. Rothman on Narch 11 th, that the next meeting of the senate would be held on Wednesday, the 6th of April, when the memorial, together with a copy of the correspondence, was accordingly sent in, and the following was the reply of the senate :-

\section{MIr. Rothman to Dr. Ayres.}

"Sir,-The senate of this university has taken into consideration the statement made by you relative to the decision on the thesis sent in by you at the last examination for the degree of M.D.; and I am directed to inform you that the examiners do not appear to the senate to have acted in opposition either to the spirit or the letter of the regulations. remain, Sir, \&c.

"R. W. Rothman, Registrar.

"University of London, April 7, 1842."

"P.S.-Circumstances prevented me yesterday from consulting the senate on the return of your thesis; but I shall not fail to do so at the next meeting, and to apprise you of the result."

\section{ELECTIONS AT THE EDINBURGH ROYAL INFIRMARY.}

\section{To the Editor of The LANCET.}

SIR,-Knowing your readiness to correct all abuses, $I$ beg leave to transmit to you a few facts regarding the manner in which the various ofticers of the Edinburgh Royal Infirmary are usually elected. To commence, then, with the election of physicians. Upon a vacancy occurring lately, on the resignation of Dr. W. Thomson, an advertisement was widely circulated requesting candidates (who were required to be fellows of one of the colleges) to send in their testimonials before a certain date; in consequence of which notice Drs. Cormack, Andrews, A. Wood, Marr, Paterson, \&c., took all possible pains to get the best possible characters printed and circulated in the shortest space of time. To the amazement of all who were not previously conversant with the usual proceedings of the managers, Dr. G. Paterson was elected. Now, although Dr. $\mathbf{P}$. is a very amiable man, and a very fair physician, there was nothing in his testimonials that conld entitle him to compete with Drs. Cormack or Andrews; and upon an inquiry being made into the causes of this election, it was stated that preference was always given to those who had previously been resident clerks, an office formerly held by Dr.
Paterson. From this answer it was clear that it was the intention of the managers to elect Dr. P., at all hazards, and against any candidates, however excellent their certificates might be, unless, perhaps, some rival antique clerk might come forward with equal claims to Dr. P.

From this statement we should be naturally led to suppose that the managers were particularly cautious in the selection of their clerks. Such, however, unfortunately is far from being the case; with the exception of Mr. M. and Dr. D., the clerks of Mr. Syme and Dr. Henderson, these offices are now filled up in a deplorably inefficient manner, and yet these clerks (almost always sons or apprentices of some of the managers) are at some future period to be thrust into that noble institution in preference to far superior men, who, not having the fortune (misfortune?) of being connected with the managers, are thus excluded from any future chance of getting appointed medical officers to the Royal Infirmary.

As a slight illustration of the state of medical incapacity of these favoured young gentlemen during the last two years, I may observe that in 1840, three out of the six re. sident clerks were rejected for either their first or second examination, and last year one of them was put back for not being able to translate a simple passage from Cicero "De Natura Deorum." Is it true that any of the medical managers charge their apprentices a higher fee than ordinary, for the use of their influence in getting them elected clerks? If it is not, why will they not allow the clerkships to be decided by a fair and open examination? Or why will they not condescend to inform the disappointed candidates upon which grounds the preference was given to the successful one?

Much might be said of their recent elec. tion of a pathological clerk and governor, but upon this point I will not at present trouble you with any observation. I remain, Sir, yours,

$$
\text { May, } 1842 .
$$

Philalethes.

\section{TESTIMONIAL TO MR. GUTHRIE.}

THE committee of officers of the medical department of the army, appointed for the purpose of expressing to Mr. Guthrie their sense of the kindness and liberality with which he had placed his lectures and hospital instructions at their service for many years, delivered to him on Tuesday, the 10th of May, a service of plate, bearing the following inscription:- -

"To G. J. Guthrie, Esq., F.R.S., \&c. "This service of plate has been presented by three hundred officers of the medical de partment of the army, the companions of his 